\title{
Modeling the relationships among psychological immunity, mindfulness and flourishing of university students.
}

\author{
Eman Khaled Essa \\ Faculty of Education, Damanhour University, Egypt \\ emmankhaled2@gmail.com
}

First draft received: 7 May 2020 Date Accepted: 1 Aug 2020 Final proof received: 21 Aug 2020

\begin{abstract}
The aim of this study is to examine the relationship among psycho-immunity, mindfulness and flourishing of university students. To achieve this a battery of instruments was applied to 140 Faculty of Education of Damanhour University students. The study tests a model for analyzing the effects of psycho-immunity and mindfulness on psychological flourishing. The findings of the study show evidence in favor of the influence of psycho-immunity and mindfulness as factors in the prediction of flourishing. finally, the results assert the importance of psycho-immunity and mindfulness in achieving flourishing.
\end{abstract}

Keywords: psychological immunity; psychological flourishing; mindfulness.

To cite this paper (in APA style):

Essa, E. Kh. (2020). Modeling the relationships among psychological immunity, mindfulness and flourishing of university students. International Journal of Education, 13(1), 37-43. doi: 10.17509/ije.v13i1.24488

\section{INTRODUCTION}

University education is considered one of the most crucial phases in students' life, as one of the most fundamental goals of the higher education institutions is to prepare their students to face their professional practical life, especially in the case of students who are going to be teachers in the near future. Recently there is an obvious interest in helping them foster their positive views and enhance their potential abilities as this can reflect on the effectiveness of their teaching and therefore on their students. As Gable and Haidt (2005) suggest that educational psychology should focus more on building the best qualities in life. One of the most important influence of positive psychology may be understanding how to achieve psychological flourishing (Seligman \& Czikszentmihalyi, 2000). Psychological immunity refers to Psychological protecting system that is defending psyche similar to the real immune system is shielding the physical body. The main function of that system is to enable individuals to manage stress (Oláh, 2005). As he refers to PIS as "a multidimensional and integrated unit of personal resilience resources and adaptive capacities that provide immunity against damage and stress" (Oláh ,2019p.1).

Some researchers such as Lindstorm and Eriksson (2005), and Olah (2005) suggest that people with effective PIS share similar personal characteristics; for example, they are able to manage the situations and they have control over the element of these situations as they can apply coping strategies effectively. In addition, they can adapt easily with the new situations and they can make use of almost all the resources available in a stressful situation.

The concept of PIS integrates the various qualities of coping personality into an integrative system based on the ideas of positive psychology which focuses on the strengths and abilities rather than inner defects and weaknesses of the personality (Olah \& Kapitány-Fövény, 2012).

According to Oláh (2005) and Oláh et al., (2012). (PIS) contains three subsystems: MonitoringApproaching Subsystem, the Creating-Executing Subsystem and the Self-Regulation Subsystem which interrelate with each other so as to enable the individual to attain a flexible adaptation and personal development.

As explained by Gombor (2009), The MonitoringApproaching Subsystem directs the individuals' attention to the physical and social environment around them. It supports them in exploring, understanding and controlling their environments, through directing their focus on expecting positive results of their efforts. It embraces different domains such as positive thinking, sense of coherence, control, social monitoring, and others. while the creatingexecuting subsystem incorporates abilities that can assist in managing the surroundings in a demanding or a stressful situation. It embodies the individual's ability to adapt with both internal and external environments in order to achieve their goals. In order to achieve this different trait are included in that 
subcategory such as creative self-concept, problem solving, self-efficacy. (Gombor,2009).

The Self-Regulating subsystem on the other hand comprises potentials that control cognitions, attention, and emotions that results from disappointment, distress or failure. As It promotes the suitable functioning of the other two subsystems by working on controlling and stabilizing the emotional reactions of individuals as Gombor (2009) suggests.

Flourishing is defined as living within an optimal range of human functioning, performance, generativity, and growth (Fredrickson \& Losada, 2005; Larsen \& Prizmic, 2008). Other researchers referred to flourishing as living through main features of psychological functioning such as "relatedness, optimism, self-acceptance, feeling competent, having supportive and rewarding relationships, contributing to the happiness of others, being respected by others" (Diener et al., 2010, p. 144). They also claimed that flourishing comprises both psychological, social wellbeing and social-psychological prosperity.

Individuals with a high level of flourishing have emotional stability, as they can interact positively in both private and social life, and they rarely suffer from psychological problems (Michalec, Keyes \& Nalkur, 2009). Flourishing enables individuals to have more active social interaction, be more open towards their life, and to be more effective community members. (Huppert, 2009; Michalec et al., 2009). Moreover, individuals with high levels of flourishing tend to have adaptive coping strategies more than those who were languishing or depressed (Faulk et al., 2013).

Studies in the field have shown that flourishing is positively related to psychological, emotional, and social well-being (Keyes, 2002), positive emotions and mindfulness (Catalino \& Fredrickson, 2011). Also, it was linked with high environmental control, positive relations with others, purpose-oriented behaviour, personal development (Telef, 2011), self-acceptance, autonomy, and low level of loneliness (Diener et al., 2010). Other studies focused on the relationships of flourishing with signs of cognitive well-being, such as comprehending abilities in diverse features of life (Gokcen et al., 2012).

As for mindfulness, it specifies paying attention during an experience or a situation (self-regulated attention) and adopting of a particular attitude towards that experience or situation (Bishop et al., 2004). This kind of self-regulated attention provides an intensive observation and awareness of the individuals' thoughts, feelings, or reactions the whole time (Keng et al., 2011). This orientation contributes to the individuals' previous knowledge with an inquisitive and tolerance stance (Bishop et al., 2004; Feldman et al., 2007; Neff \& Germer, 2013). In the same context, Hayes and Feldman (2004) and Keng et al. (2011) suggest that mindfulness is a very significant psychological concept; it is considered as an important indicator of flourishing. According to that broad effect it may be acceptable to suggest that having higher levels of mindfulness plays an important role in defending people against psychological problems to the extent that they can experience higher level of flourishing. According to Langer (1997) mindfulness has four main subdomains which are novelty producing, novelty seeking, engagement and flexibility. The first one refers to the ability of the individual of improving a new perspective to deal with the surrounding environment, while the second focuses on devoting one's abilities on looking for new motivational aspects all the time.as for the third domain, it refers to a high level of awareness and participation in whatever situations that face the person. Regarding the last domain, it focuses on the ability of accepting and coping while focuses on only what really matters in the individuals' life.

Mindfulness seems to enhance the skill of recognizing, and thus individuals are able to take enough time to reflect on problems and bad experiences in a relatively realistic way without triggering negative emotional conditions related to the situation. This gives them the opportunity to reflect a deeply and reach alternative coping resources or strategies (Shapiro et al., 2006). In addition, mindfulness may alleviate the consequences on wellbeing and flourishing. Equally, individuals who have low levels of mindfulness are more likely to react in some more negative ways that lead to depression instead of coping and this may damage their approaches of flourishing (Thomas, 2011).

Considering the relationships of psychological immunity system, mindfulness, and flourishing with positive mental health indicators, it seems possible that flourishing may be enhanced by mindfulness and thus it also may help to improve flourishing. In the light of the reciprocal relationships between mindfulness, coping competence, and flourishing with adaptive and maladaptive constructs which have been demonstrated by previous studies, mindfulness may influence flourishing via coping competence. The goal of this study is to explore this mediating effect as well as the associations of mindfulness, coping competence, and flourishing. In this study it was hypothesized that as mindfulness increases, flourishing may increase or vice versa and that coping competence may have a mediating role in this relationship.

\section{METHOD \\ Participants}

The recent study addressed a sample of (140) students of the third year in the faculty of education. Students were randomly selected after briefing them about the study, and their approval of participation was obtained. The study used three questionnaires: the mindfulness questionnaire, flourishing questionnaire, and the psychological immunity system (PIS). Each of them was administrated to students during lecture time by the responsible lecturers at that particular time after explaining the concepts and clarifying any doubts according to the clarifications given by the researcher. 


\section{Measures \\ Langer Mindfulness Scale}

It consists of 19 items and 4 subscales; namely, novelty producing, novelty seeking, engagement, and flexibility. The self-report scale designed to assess the level of mindfulness. Items are rated on a 5point Likert scale from 1 (almost always) to 5 (almost never). Studies highlight a high internal consistency as Cronbach's alpha range from (0.82 to 0.87 ), and good test-retest reliability (Pirson et al., 2015). In the recent study the consistency measured by two methods the first one Cronbach's alpha which reached (0.89). while the other method was the test retest which reached (0.90) for the total mark.

Flourishing Scale (FS).

The FS (Diener et al., 2010) measures psychological and social well-being. It is a brief 8-item measure that consists of items on social relationships, having a life of purpose and meaning, engagement and interest in activities, self-respect and optimism, and feelings of competence and ability in meaningful activities. Flourishing Scale is based on the respondent's subjective perspective and it ranges from 1 (strongly disagree) to 7 (strongly agree), and the total score is the sum of all scores, with higher scores indicating higher levels of flourishing. (Diener et al.,2010) conducted a principal factor analysis which showed a single factor, so there are no subscales. They also found good reliability at $\alpha=.87$. Construct validity was determined through convergence with similar scales and discrimination from scales measuring different constructs. In the present study it obtained reliability of (0.87) and internal consistency at (0.89). which are considered good indicators to be used in the study.

\section{Psychological Immune System Inventory (PISI)}

The instrument was prepared by (Oláh et al., 2012) and it is meant to measure the level of psychological immunity of the individual. It consists of 80 items that stand for 16 different factors. These 16 subscales are comprised into three subsystems based on their main psychological functions. These subsystems are: The Monitoring-Approaching Subsystem which includes Positive Thinking, Sense of Coherence, Sense of Control, Sense of Self Growth, Change and Challenge Orientation, Social Monitoring, and Goal Orientation. The Creating-Executing Subsystem (2) includes Creative Self-Concept, Problem Solving, Self-Efficacy, Social Mobilizing Capacity and Social Creating Capacity. The Self-Regulating Subsystem (3) contains Synchronicity, Impulse Control, Emotion Control and Irritability control. The items are simple statements that the participants required to respond to on a 4-point scale;1 - completely does not describe me to 4 completely describes me.

In previous research, the Cronbach's Alpha ranged from (.62 to .80) for all sixteen subscales, and the questionnaire also has a quite high convergent and discriminant validity (Oláh, 2005). The Cronbach's
Alpha values found in this study are presented below in Table (1)

Table 1

Reliability of PISI subsystems

\begin{tabular}{ll}
\hline \multicolumn{1}{c}{ Subsystem } & Cronbach's alpha \\
\hline $\begin{array}{l}\text { Monitoring - Approaching } \\
\text { Subsystem (MAS) }\end{array}$ & 0.80 \\
\hline $\begin{array}{l}\text { Creating Executing } \\
\text { Subsystem (CES) }\end{array}$ & 0.82 \\
\hline $\begin{array}{l}\text { Self-regulating Subsystem } \\
\text { (SRS) }\end{array}$ & 0.85 \\
\hline Total & 0.86 \\
\hline
\end{tabular}

\section{RESULTS}

To answer the first question: what are the levels of psychological immunity among the sample of the study? regarding the levels of (PIS) the means and standard deviation for the subsystems and the total score were measured, as presented in table (2)

Table 2

Means and Standard Deviation of PIS

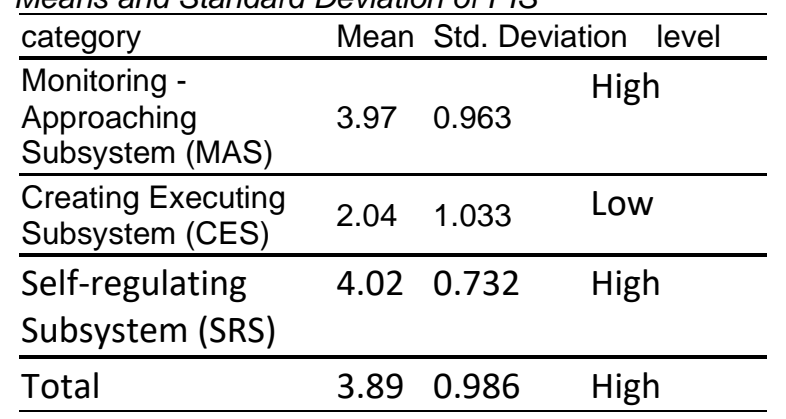

According to the data analytical done for the scales that were applied in this study, if the means of scores are below (2.3) the level is considered to be low, if the mean is between (2.42-3.71) the level is average while it refers to high level if comes in the range of (3.72-5).

As the data in Table 2 shows, the total level of (PIS) of the sample of the study is at average level. As for the subsystems, the data reveals that (SRS) came at the highest level amongst the three subsystems, while the subsystem (CES) came at the lowest level.

Regarding the second question "what are the levels of mindfulness of the university students? Means and Std. Deviations were calculated as shown in the following table.

Table 3

Means and Std. Deviations of mindfulness

\begin{tabular}{llll}
\hline \multicolumn{1}{c}{ Category } & Mean & St.Deviation Level \\
\hline Novelty producing & 3.32 & 0.854 & Average \\
\hline Novelty seeking & 3.36 & 0.850 & Average \\
\hline Engagement & 3.32 & 0.862 & Average \\
\hline Flexibility & 3.51 & 0.712 & Average \\
\hline Total & 3.33 & & Average
\end{tabular}


As presented in table 3 , the level of mindfulness among the students were average on both the subcategories and the total mark. In addition, it seems that the sub-category flexibility ranged higher than the other categories.

Regarding the main question asking, "what is the relationship among the mindfulness, psychological immunity and flourishing according to the direct and indirect relationship?" The recent study proposed a theoretical model that suggests that mindfulness is positively related to psychological immunity system which in turn has predictive power of flourishing, thus playing a mediator role between mindfulness and flourishing. That means that the direct effect of the mindfulness on flourishing differs from indirect effect with psychological immunity as a mediator.

Table 4

The Goodness of fit parameters for the complete meditation model

\begin{tabular}{cccccc}
\hline $\mathrm{X}^{2} \mathrm{df}$ & $\mathrm{P}$ & $\mathrm{CFI}$ & $\mathrm{NFI}$ & $\mathrm{TLI}$ & $\mathrm{RESEA}$ \\
\hline 1.14 & 0.572 & 0.991 & 0.961 & 0.993 & 0.0606 \\
\hline
\end{tabular}

An initial analysis of the resulting parameters indicates that the model fit the empirical data in an acceptable way. Regarding the direct effects of mindfulness and (PIS) on flourishing it can be presented as in figure (1) obtained by path analysis. it seems that all sub systems of (PIS) and subcategories of mindfulness has a direct effect on flourishing and that flexibility has the strongest effect on flourishing while the effect of (PSI) sub system (MAS) was not significant. As regards the direct effects of (PIS) on mindfulness all paths were significant.

\section{Figure 1}

Direct effect of mindfulness and (PSI) on flourishing

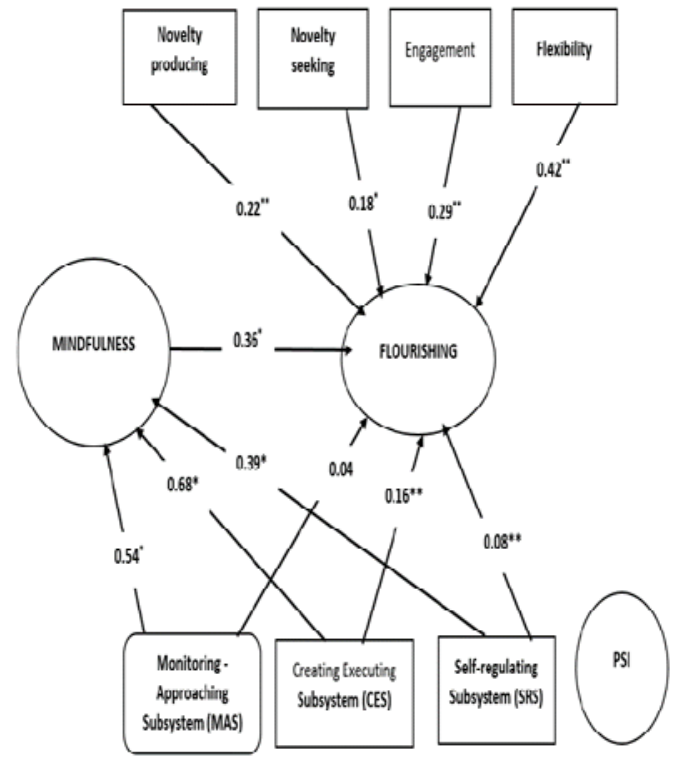

As illustrated in figure (1) the model shows a direct impact of both psychological immunity and mindfulness on flourishing as subcategory (flexibility) came with the highest impact. This implies the direct correlation among the three variables of the suggested model.

\section{DISCUSSION}

This research aimed to investigate the mediating effect of psychological immunity system and mindfulness on flourishing. The findings showed that there were significant relationships among these variables. As proposed in the theoretical model of the study, results verified that the relationship between mindfulness and flourishing was partially mediated by(PIS), which means that, as mindfulness surges in this model, flourishing also rises and (PIS) has a mediating role in that escalation. According to those results, in having a high level of psychological immunity, students will also have higher levels of Monitoring - Approaching Creating Executing Self-regulating in addition to high levels of novelty producing, novelty seeking, engagement and flexibility and thus they may have better flourishing level, which agrees with the findings of previous studies (Bohmeijer et al., 2015).

Likewise, mindful students experience more positive affect (Brown \& Ryan, 2003), as they are less sensitive to emotionally threatening stimuli (Creswell et al., 2007), tend to be more optimistic, to endorse more positive self-views (Aspinwall \& Richter, 1999), and to engage in more active coping strategies (i.e., problem solving) (Weinstein, et al., 2009). Thus, students with high level of mindfulness to perceive themselves as a "flourished" as referred by (Ryan \& Frederick, 1997) and to have stronger psychological immunity system.

The results show that mindfulness affects flourishing both directly and indirectly via (PSI). People who have higher level of mindfulness are more likely to be high in flourishing. Implications of these findings show that mindfulness and psychological immunity system play a key role in supporting psychological well-being presented in flourishing. Thus, educators who are dealing with students in the university level may need to focus more on these psychological variables to help university students to have better psychological and mental health and increase their flourishing levels. Furthermore, mindfulness-based interventions (e.g., Segal et al., 2002) may be effectively used by educators and counselors to raise the awareness of individuals to understand and attend to stressful thoughts and emotions they may face during their educational life (Schroevers \& Brandsma, 2010). However, future research should consider other cognitive and emotional variables that may moderate the relationships of mindfulness with flourishing. Another implication of these findings is support for prior researches that indicated the positive effects of mindfulness and flourishing on academic performance, which draw the attention towards intervention training programs that can help students developing their 
levels of mindfulness. As this can contribute not only to their flourishing levels and PIS but also to their academic and learning outcomes.

\section{CONCLUSION}

This research contributes a better understanding of the causal relationship among three important psychological concepts that affect university students 'life. The findings of the study show evidence in favor of the influence of psycho-immunity and mindfulness as factors in the prediction of flourishing. This leads to the suggestion that to enhance PIS and mindfulness could be highly beneficial for flourishing as the direct effect of the mindfulness on flourishing differs from indirect effect with psychological immunity as a mediator according to the obtained results. These findings may lead the way for further studies especially in the field of vocational training, as these three concepts not only affect the students as individuals, but also have a major impact on them as teachers in the near future. Mindfulness sub-categories;(Novelty producing, Novelty seeking, Engagement, Flexibility) for example may be considered as main characteristics of both students and teachers. Therefore, focusing on these concepts could be a long-term investment that has its positive effects on all of the components of the educational process.

\section{REFERENCES}

Akın, A., \& Fidan, M. (2012, April). The validity and reliability of the Turkish version of the Flourishing Scale. In 3rd International Conference on New Trends in Education and their Implications (ICONTE-2012), April (pp. 26-28).

Akin, A., Kaya, M., Turan, M. E., Akin, U., \& Karduz, F. F. A. (2014). The validity and reliability of the Turkish version of the coping competence questionnaire. Journal of Educational \& Instructional Studies in the World, 4(4).

Aspinwall, L. G., \& Richter, L. (1999). Optimism and self-mastery predict more rapid disengagement from unsolvable tasks in the presence of alternatives. Motivation and Emotion, 23(3), 221245.

Baer, R. A. (2003). Mindfulness training as a clinical intervention: A conceptual and empirical review. Clinical psychology: Science and practice, 10(2), 125-143.

Baer, R. A., Lykins, E. L., \& Peters, J. R. (2012). Mindfulness and self-compassion as predictors of psychological wellbeing in long-term meditators and matched no meditators. The Journal of Positive Psychology, 7(3), 230-238.

Baer, R. A., Smith, G. T., \& Allen, K. B. (2004). Assessment of mindfulness by self-report: The Kentucky Inventory of Mindfulness Skills. Assessment, 11(3), 191-206.

Baron, R. M., \& Kenny, D. A. (1986). The moderatormediator variable distinction in social psychological research: Conceptual, strategic, and statistical considerations. Journal of personality and social psychology, 51(6), 1173 1182.

Bishop, S. R., Lau, M., Shapiro, S., Carlson, L., Anderson, N. D., Carmody, J., ... \& Devins, G. (2004). Mindfulness: A proposed operational definition. Clinical psychology: Science and practice, 11(3), 230-241.

Bohlmeijer, E. T, Lamers, S. M., Westerhof, G. J.\& Glas, C. A. (2015). The bidirectional relation between positive mental health and psychopathology in a longitudinal representative panel study. The Journal of Positive Psychology, 10(6), 553-560.

Brown, K. W., \& Ryan, R. M. (2003). The benefits of being present: mindfulness and its role in psychological well-being. Journal of personality and social psychology, 84(4), 822.

Buchheld, N., Grossman, P., \& Walach, H. (2002). Measuring mindfulness in insight meditation (Vipassana) and meditation based psychotherapy: The development of the Freiburg Mindfulness Inventory (FMI). Journal for Meditation and Meditation Research, 1, 11-34.

Cash, M., \& Whittingham, K. (2010). What facets of mindfulness contribute to psychological wellbeing and depressive, anxious, and stressrelated symptomatology? Mindfulness, 1(3), 177182.

Catalino, L. I., \& Fredrickson, B. L. (2011). A Tuesday in the life of a flourisher: The role of positive emotional reactivity in optimal mental health. Emotion, 11(4), 938-950.

Catak, P. D. (2012). The Turkish version of the Cognitive and Affective Mindfulness Scalerevised. Europe's Journal of Psychology, 8, 603619.

Compas, B. E., Connor-Smith, J. K., Saltzman, H., Thomsen, A. H., \& Wadsworth, M. E. (2001). Coping with stress during childhood and adolescence: problems, progress, and potential in theory and research. Psychological bulletin, 127(1), 87-127.

Creswell, J. D., Way, B. M., Eisenberger, N. I., \& Lieberman, M. D. (2007). Neural correlates of dispositional mindfulness during affect labeling. Psychosomatic medicine, 69(6), 560565.

Diener, E., Wirtz, D., Tov, W., Kim-Prieto, C., Choi, D. W., Oishi, S., \& Biswas-Diener, R. (2010). New well-being measures: Short scales to assess flourishing and positive and negative feelings. Social Indicators Research, 97(2), 143156.

Diehl, M., Hay, E. L., \& Berg, K. M. (2011). The ratio between positive and negative affect and flourishing mental health across adulthood. Aging \& Mental Health, 15(7), 882-893.

Faulk, K. E., Gloria, C.T., \& Steinhardt, M. A. (2013). Coping profiles characterize individual flourishing, languishing, and depression. Anxiety, 
Stress \& Coping: An International Journal, 26(4),378-390.

Feldman, G., Hayes, A., Kumar, S., Greeson, J., \& Laurenceau, J.P. (2007). Mindfulness and emotion regulation: The development and initial validation of the Cognitive and Affective Mindfulness Scale-Revised (CAMS-R). Journal of Psychopathology and Behavioral Assessment, 29(3), 177-190.

Fredrickson, B. L., \& Losada, M. F. (2005). Positive affect and the complex dynamics of human flourishing. American Psychologist, 60(7), 678686.

Gable, S. L., \& Haidt, J. (2005). What (and why) is positive psychology? Review of General Psychology, 9(2), 103-110.

Gokcen, N., Hefferon, K., \& Attree, E., (2012). University students' constructions of 'flourishing' in British higher education: An inductive content analysis. International Journal of Wellbeing, 2(1), 1-21.

Gombor, A. (2009). Burnout in Hungarian and Swedish emergency nurses: demographic variables, work-related factors, social support, personality, and life satisfaction as determinants of burnout. (Doctoral dissertation) University of Eötvös Loránd, Budapest https://www.yumpu.com/en/document/view/1570 2865/thesis/3.

Hardy, L., Jones, J. G., \& Gould, D. (1996). Understanding psychological preparation for sport: Theory and practice of elite performers. John Wiley \& Sons Inc.

Hayes, A. M., \& Feldman, G. (2004). Clarifying the construct of mindfulness in the context of emotion regulation and the process of change in therapy. Clinical Psychology: Science and Practice, 11(3), 255-262.

Huppert, F. A. (2009). Psychological well-being: Evidence regarding its causes and consequences. Applied Psychology: Health and Well-being, 1(2), 137-164.

Kabat-Zinn, J. (2005). Coming to our senses: Healing ourselves and the world through mindfulness. Hachette Books.

Kabat-Zinn, J. (2009). Wherever you go, there you are: Mindfulness meditation in everyday life. Hachette Books.

Keng, S.L., Smoski, M.J., \& Robins, C.J. (2011). Effects of mindfulness on psychological health: A review of empirical studies. Clinical Psychology Review, 31(6), 1041-1056.

Keyes, C. L. M. (2002). The mental health continuum: From languishing to flourishing in life. Journal of Health and Social Behavior, 43, 207-222.

Langer, E. J. (1997). Matters of mind: Mindfulness/mindlessness in perspective. Consciousness and cognition, 1(3), 289-305.

Larsen, R. J., \& Prizmic, Z. (2008). The regulation of emotional wellbeing: Overcoming the hedonic treadmill. The science of subjective wellbeing ,258-289). Guilford.

Eriksson, M., \& Lindström, B. (2005). Validity of Antonovsky's sense of coherence scale: a systematic review. Journal of Epidemiology \& Community Health, 59(6), 460-466.

Lopez, C. M., Beglea, A. M., Dumas, J. E., \& de Arellanoa, M. A. (2012). Parental child abuse potential and subsequent coping competence in disadvantaged preschool children: Moderating effects of sex and ethnicity. Child Abuse \& Neglect, 36(3), 226-235.

Michalec, B., Keyes, C. L. M., \& Nalkur, S. (2009). Flourishing. In: Lopez, S.J. (Ed.), The encyclopedia of positive psychology, I, 391-394. Wiley-Blackwell.

Moore, P. (2008). Introducing mindfulness to clinical psychologists in training: An experiential course of brief exercises. Journal of Clinical Psychology in Medical Settings, 15(4), 331-337.

Moreland, A. D., \& Dumas, J. E. (2008). Evaluating child coping competence: Theory and measurement. Journal of Child Family Studies, 17(3), 437-454.

Neff, K. D., \& Germer, C. K. (2013). A pilot study and randomized controlled trial of the mindful selfcompassion program. Journal of Clinical Psychology, 69(1), 28-44.

Nicolas, M., \& Jebrane, A. (2008). Relationships between coping strategies and defense mechanisms in sport performance. Psychological Reports, 103(3), 735-744.

Oláh, A. (2005) Emotions, coping and the optimal experience. Trefort Kiadó .

Oláh, A., \& Kapitány-Fövény, M. (2012). Ten years of positive psychology. Magyar Pszichológiai Szemle, 67(1),19-45. https://doi.org/10.1556/mpszle.67.2012.1.3

Oláh, A. (2019). Positivity is an up-to-date predictor of well-functioning instead of a eudaemon. Asian Journal of Social Psychology,22,143-145. https://doi: 10.1111/ajsp.12362.

Pirson, M., \& Langer, E. (2015). Developing the langer mindfulness scale. Academy of Management Proceedings 10.5465/AMBPP.2015.11308abstract.

Ramones, S. M. (2011). Unleashing the power: Anthony Robbins, positive psychology, and the quest for human flourishing. Capstone Project, Master of Applied Positive Psychology, University of Pennsylvania.

Rasmussen, M. K., \& Pidgeon, A. M. (2011). The direct and indirect benefits of dispositional mindfulness on self-esteem and social anxiety. Anxiety, Stress and Coping, 24, 227233. https://doi:10.1080/10615806.2010.515681.

Ryan, R. M., \& Frederick, C. (1997). On energy, personality and health: subjective vitality as a dynamic reflection of well-being. Journal of Personality, 65, 529-565. 
Schroder, K. E. E. (2004). Coping competence as predictor and moderator of depression among chronic disease patients. Journal of Behavioral Medicine, 27, 123-145.

Schroder, K. E. E., \& Ollis, C. L. (2013). The Coping Competence Questionnaire: A measure of resilience to helplessness and depression. Motivation and Emotion, 37, 286302.

Schroevers, M. J., \& Brandsma, R. (2010). Is learning mindfulness associated with improved affect after mindfulness-based cognitive therapy? British Journal of Psychology, 101, 95-107.

Segal, Z. V., Williams, J. M. G., \& Teasdale, J. D. (2002). Mindfulness-based cognitive therapy for depression: A new approach to preventing relapse. Guilford Press.

Seligman, M., \& Csikszentmihalyi, M. (2000). Positive psychology: An introduction. American Psychologist, 55, 5-14.

Shapiro, S. L., Carlson, L., Astin, J. A., \& Freedman, B. (2006). Mechanisms of mindfulness. Journal of Clinical Psychology, 62, 373-386

Sobel, M. E. (1982). Asymptotic confidence intervals for indirect effects in structural equation models. In: Leinhardt, S. (Ed.), Sociological methodology, 290-312. American Sociological Association.

Telef, B. B. (2011). The validity and reliability of the Turkish version of the Psychological Well-being Scale. Paper presented at the 11th National Congress of Counseling and Guidance.

Thomas, C. (2011). A review of the relationships between mindfulness, stress, coping styles and substance use among university students. Edith Cowan University.

Weinstein, N., Brown, K., \& Ryan, R. (2009). A multimethod examination of the effects of mindfulness on stress attribution, coping, and emotional wellbeing. Journal of Research in Personality, 43, 374-385.https://doi:10.1016/j.jrp.2008.12.008. 